\title{
El Museo Paleontológico de Elche apuesta desde sus orígenes por que la ciudadanía se implique en su gestión diaria
}

\author{
Después de más de 20 años de esfuerzo y dedicación del Grupo Cultural Paleontológico de Elche en \\ favor de la riqueza patrimonial de la provincia, el Museo Paleontológico de Elche (MUPE) se inauguró en \\ el año 2004. Estamos ante un museo que no surge al amparo de un centro de investigación o universidad, \\ sino a partir de las inquietudes de un grupo de aficionados. En la actualidad la gestión del museo corre a \\ cargo de la Fundación Cidaris.
}

\begin{abstract}
Ainara Aberasturi Rodríguez | Fundación Cidaris-MUPE
Ignacio Fierro Bandera | GeaLand Patrimonio

José Manuel Marín | Fundación Cidaris-MUPE

Esteban José Sánchez Ferris | Fundación Cidaris, responsable Proyecto FOPALI. Fósiles y Patrimonio de Alicante

URL de la contribución <www.iaph.es/revistaph/index.php/revistaph/article/view/4188>
\end{abstract}

En el año 1982, tres años antes de la Ley 16/1985, de 25 de junio, de Patrimonio Histórico Español, un grupo de aficionados a la paleontología, ante motivaciones e intereses comunes, decide reunirse y crear el Grupo Cultural Paleontológico de Elche (GCPE). Sin ser conscientes, estaban dando el primer paso para lo que años más tarde daría lugar al actual Museo Paleontológico de Elche (MUPE).

EI GCPE supuso un punto de encuentro para los aficionados en paleontología de Elche y alrededores. Así, y tras crear una junta directiva, comenzaron los contactos con el Ayuntamiento de Elche para conseguir los objetivos inicialmente marcados: unir las colecciones y disponer de un espacio donde poder albergarlas y darlas a conocer a la sociedad. Con el tiempo se fueron incorporando nuevos miembros al grupo y se establecieron contactos con diferentes universidades españolas y museos de todo el mundo. En dicho momento también comienza a publicarse la revista de paleontología y mineralogía Cidaris, de la que se han editado 32 números. La riqueza paleontológica de Elche comenzaba a conocerse y también se detectaba la destrucción de yacimientos, aspectos que ya por el entonces eran denunciados.

El año 1996 (dos años antes de la entrada en vigor de la Ley de Patrimonio Cultural Valenciano) supone un hito para el Grupo Cultural ya que la colección es declarada como Colección Museográfica de Paleontología e incorporada a la Red de Museos de la Comunidad Valenciana (Diari Oficial de la Generalitat Valenciana, del 14 de mayo). A partir de este momento comienzan a organizarse actividades para difundir la paleontología.

El interés creciente por parte de la sociedad por conocer el patrimonio paleontológico y el trabajo del GCPE hace que el Ayuntamiento de Elche adapte un espacio para albergar el actual Museo Paleontológico de Elche, el cual se inaugura el 3 de diciembre de 2004.

Desde entonces, el museo se ha convertido en un referente en Alicante al ser el único museo de paleontología de toda la provincia que desarrolla proyectos de investigación y que han desembocado por ejemplo en dos tesis doctorales (FIERRO, 2015; SÁNCHEZ-FERRIS, 2016), proyectos de conservación y de difusión del patrimonio geológico y paleontológico (ABERASTURI; SÁNCHEZ; FIERRO et ál., 2014), tres pilares básicos sobre los que se sustenta todo museo.

Estamos ante un museo que no surge al amparo de un centro de investigación o universidad; nace a partir de las inquietudes de un grupo de aficionados y que con el tiempo incorpora geólogos y biólogos a la institución. En 


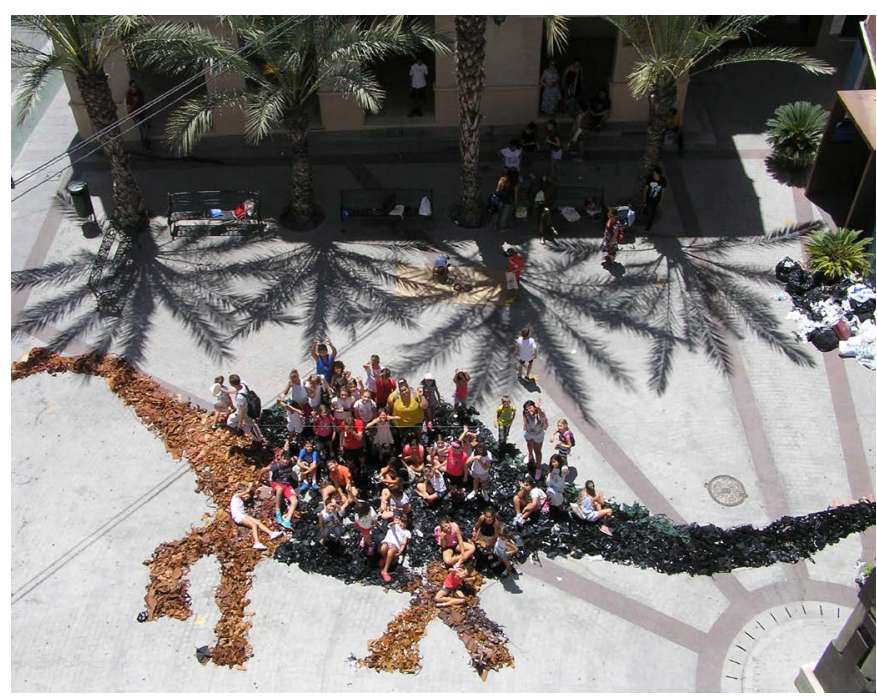

La implicación de la sociedad en el museo es una herramienta fundamental. En la imagen un grupo realiza un gran dinosaurio con materiales de una empresa de calzado de la ciudad | foto MUPE

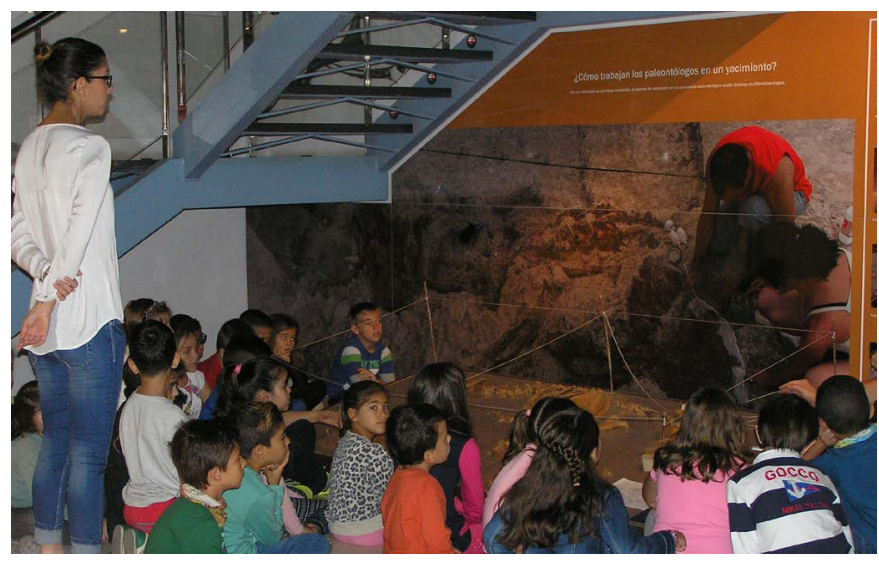

Las visitas de escolares en el museo son una constante, conociendo desde pequeños parte del patrimonio natural del entorno y disfrutando a la vez que aprenden | foto MUPE

este sentido es de destacar que el MUPE apuesta por un museo en el que la sociedad se implique en su día a día. Los museos han evolucionado, quedando atrás modelos que podríamos definir como "museos escaparate", dando lugar a espacios abiertos a la sociedad, de concienciación, buscando en todo momento la participación y su uso como lugares donde el aprendizaje y el entretenimiento van parejos. Resulta fundamental, por tanto, la implicación de la ciudadanía en el museo, aspecto que favorecerá la conservación y divulgación del patrimonio paleontológico.
Con todo, el MUPE se encuentra inmerso en un proyecto de divulgación de las ciencias de la Tierra denominado proyecto didacPAL, gracias al cual se realizan actividades muy diversas, que van desde visitas guiadas, talleres, conferencias, exposiciones hasta itinerarios geológicos y paleontológicos que sirven para dar a conocer el patrimonio. Además, desde el año 2007 también se desarrolla un proyecto de gestión del patrimonio paleontológico, denominado Proyecto FOPALI (Fósiles y Patrimonio de Alicante). Hasta la fecha son numerosos los trabajos realizados en este sentido, que son también dados a conocer a la sociedad, buscando con ello sinergias con la ciudadanía para comprender la fragilidad del patrimonio paleontológico y favorecer su conservación.

A lo largo del año, es habitual que algún visitante venga al museo con un fósil que ha recogido en el campo, siendo necesario explicar la situación de la legislación actual, desde la concienciación. En este sentido cabe destacar que el patrimonio paleontológico es un gran desconocido, mientras la sociedad comprende que el hallazgo de un elemento arqueológico hay que comunicarlo y tomar las medidas oportunas, no ocurre lo mismo en el marco paleontológico. Es más, mientras se sobreentiende la necesidad de realizar seguimientos arqueológicos durante la realización de determinadas obras cuesta plantear lo mismo en el caso paleontológico. Esta labor de información también se realiza desde el museo.

\section{BIBLIOGRAFÍA}

- ABERASTURI, A.; SÁNCHEZ, E. J.; FIERRO, I.; MARÍN, J. M.; NAVARRO, J. (2014) El proyecto didáctico del Museo Paleontológico de Elche: didacPAL. En XVIII Simposio sobre la enseñanza de la geología (18 ${ }^{\circ}$ 2014. Bilbao). sl: Universidad del País Vasco, Servicio Editorial, 2014, pp. 165-174

- FIERRO, I. (2015) Caracterización patrimonial de los depósitos laminados de las cuencas de Lorca. Elche: Universidad Miguel Hernández, 2015 (ver sección Reseñas)

- SÁNCHEZ-FERRIS, E. J. (2016) Patrimonio geológico y paleontológico del término municipal de Elche: el Clot de Galvany y el Pantano. Tesis doctoral inédita, Universidad de Valencia (ver sección Reseñas) 